\title{
SOBRE ARCOS-ÍRIS E BORBOLETAS: OS CLÁSSICOS, AS CIÊNCIAS HUMANAS E A ÁFRICA ${ }^{1}$
}

Michael Lambert ${ }^{2}$

\section{RESUMO}

O propósito do ensino de Ciências Humanas e, em particular, dos Clássicos, em um contexto Africano pós-colonial, tem sido o tema de intensos debates nas universidades Sul-Africanas e Africanas. Neste trabalho, eu contribuo com esse debate ao considerar como a Universidade de Ibadan na Nigéria se apropriou da tradição clássica em um contexto pós-colonial e quais classicistas na África do Sul podem aprender com o exemplo de Ibadan. Uma breve discussão sobre as complexas relações patrono-cliente, que sustentam a sobrevivência de um forte Departamento de Estudos Clássicos em Ibadan, tem a intenção de sugerir como a política cultural local, inextricavelmente ligada à história da instituição e ao departamento, irá afetar a transformação do curriculum das universidades africanas. Os Departamentos de Estudos Clássicos nas universidades sul-africanas terão que negociar seus próprios caminhos para a transformação, ao refletirem sobre por que os Estudos Clássicos deveriam continuar a ser ensinados em seus contextos sul-africanos específicos.

"Há um arco-íris lá fora, senhor. Você já viu? Como se diz arco-íris em grego?"

“Algo relacionado à deusa Íris, eu acho. Talvez "I $\rho ı$ s.

Portanto, arcoiris em espanhol."

"E em latim?"

"Obviamente o mesmo. Íris."

"E borboleta?"

"Eu realmente não sei. Por que você está me perguntando isso?"

"Eu vi uma ontem pela primeira vez em muito tempo. Do meu curso de italiano, eu sei

que é farfalla em italiano."

\footnotetext{
${ }^{1}$ Discurso do presidente, Associação Clássica da África do Sul, 30 Conferência Bienal, Universidade do Estado Livre, Bloemfontein, 8-11/julho/2013. Este artigo foi publicado originalmente na revista ACTA CLASSICA LVII (2014) 1-15. Foi traduzido com anuência do autor e do editor da revista. Tradução de Mônica Borges Lopes - monica.b.lopes@gmail.com

2 Professor Livre-Docente - Universidade de KwaZulu-Natal, Pietermaritzburg, África do Sul. E-mail: lambert@ukzn.ac.za
} 
“E mariposa em espanhol. Borboleta em português."

"E papillon em francês, senhor."

“Bem, eu não acho que as línguas românicas irão nos ajudar.

Lembre-se que também há papilio a palavra latina para mariposa."

"E uma borboleta, senhor. Acabei de checar isso no Google."

Pensando sobre um diálogo assim, típico em uma aula introdutória de línguas clássicas, quando os olhos perdem o brilho pela simples menção do Meio Indicativo Imperfeito dos verbos contratuais e um dos alunos mais tagarelas, genuinamente interessado em etimologia, tenta usar uma tática de distração, eu imaginei que uma conversa assim poderia ter acontecido em qualquer lugar; não houve nada neste diálogo que indicasse especificamente tratar-se de algo sul-africano, ou britânico, ou americano, ou europeu. Além disso, o uso do Google na sala de aula simplesmente enfatizou a universalidade desse momento de aprendizado contemporâneo: isso foi educação globalizada, um exemplo do ensino de uma língua clássica transcendendo barreiras nacionais. Todavia, se eu fosse "problematizar" essa conversa e mencionasse que o professor é um homem sul-africano branco, que o aluno também é um homem branco, porém não sul-africano, que a localização cheira a privilégio e classe, evidente na grande variedade de línguas mencionadas, então, a conversa aparentemente inocente sobre arcos-íris e borboletas não é tão inocente assim, mas torna-se aprisionada nos discursos sobre raça, classe, gênero e poder o que assusta a todos nós, e, em especial, o ensino dos Clássicos na África do Sul ${ }^{3}$. Voltarei para arcos-íris e borboletas, contudo, eu gostaria de começar direcionando seu olhar para além das nossas fronteiras, em direção ao norte, para alguns diálogos norte-sul. Mahmood Mamdani, atualmente o Diretor do Instituto Makerere de Pesquisas Sociais da Universidade Makerere em Uganda, argumentou, em um discurso de abertura, a importância da pesquisa em uma universidade, que o modelo voltado para o mercado, dominante nas universidades africanas, tem nutrido uma "cultura de consultoria", o que tem tido um impacto negativo na qualidade dos cursos e pesquisas de pós-graduação ${ }^{4}$. Mamdani escreve:

"Hoje em dia, a vida intelectual nas universidades foi reduzida a meras e básicas atividades em sala de aula. Seminários e workshops extracurriculares passaram a ser realizados em hotéis. A presença em

\footnotetext{
3 Veja Lambert 2011.

${ }^{4}$ Discurso dado em uma Conferência sobre a Disseminação de Pesquisas e Inovações na Universidade Makerere, Uganda (27/abril/2011). Distribuído para os funcionários da UKZN como um comunicado do Vice-Reitor chamado de "A Importância da Pesquisa em uma universidade."
} 
workshops vem junto com auxílio transporte e diárias. Tudo isso faz parte de um processo maior, a ONG-ização da universidade. Trabalhos acadêmicos se tornaram apresentações em PowerPoint, como as corporativas. Os acadêmicos leem cada vez menos. Um coral de palavras murmuradas tomou o lugar de debates animados"

Mamdani continua dizendo que a questão mais importante confrontando a educação superior na África no momento é "o que significa ensinar ciências humanas e ciências sociais... no contexto Africano pós-colonial." Ele pergunta: "O que significa ensinar ciências humanas e ciências sociais em um local onde os paradigmas intelectuais dominantes são produtos não da própria experiência da África, mas de uma experiência particular do Ocidente ${ }^{5}$ ?" Como um antídoto para a cultura de consultoria, o que resulta na coleta de informações para que possamos solucionar problemas pré-empacotados, Mamdani faz um apelo para o retorno ao que ele chama de pesquisa "básica", o que, como a pergunta acima ilustra, é "identificar e questionar pressupostos que movem o próprio processo da produção de conhecimentos." Ilustrando o fato de que a África e não a Europa ou a América do Norte deverá produzir a maioria dos pós-graduados africanos, Mamdani cita o caso da Nigéria, que tinha uma universidade com 1.000 alunos na época da independência, mas trinta anos mais tarde, em 1991, ela já tinha 41 universidades com 131.000 alunos. O simples peso desses números já demonstra que o modelo colonial de "primeiro diploma na África e diploma de pós-graduação no exterior", simplesmente, não é mais factível ou desejável para a maioria dos graduados africanos. Os africanos precisam desenvolver seus próprios programas de pós-graduação para africanos que podem até se engajar com os paradigmas intelectuais Ocidentais, mas que devem questioná-los incessantemente.

Embora Mamdani não se refira diretamente ao estudo dos Clássicos em seu trabalho, eu gostaria de extrair algumas das implicações dos argumentos de Mamdani para nós, como classicistas aqui na África do Sul, focando nas minhas experiências em 2012 no único Departamento de Estudos Clássicos em uma universidade nigeriana - a Universidade de Ibadan.

A Universidade de Ibadan, situada na região sudoeste do país, a mais ou menos 120 quilômetros de Lagos, é a mais antiga universidade da Nigéria (fundada em 1948) e é considerada, dentre as outras universidades nigerianas no mercado (federais, estaduais e privadas), como "a primeira e a melhor" e

\footnotetext{
${ }^{5}$ De maneira análoga, Mazrui, há mais de vinte anos: “...há uma crise de identidade confrontando todas as universidades africanas modernas - e a aura de mistério da Grécia Antiga está no cerne de tudo" (Goff, 2013:190).
} 
como "o principal centro de pesquisa da Nigéria e da África subsaariana". Embora Ibadan não seja mais a principal universidade na Nigéria (rankings internacionais dão à Universidade de Lagos uma nota maior) nem da África subsaariana, onde ela foi ofuscada por algumas universidades sul-africanas, ela ainda é a universidade nigeriana mais conhecida internacionalmente e tem muito orgulho de seus dias de glória. Como a Universidade do Zimbábue, Ibadan teve uma relação especial com a Universidade de Londres e, entre 1950 e 1964, ofertou cursos (e diplomas) honorários de quatro anos, que eram monitorados e concedidos pela Universidade de Londres. Nesses anos, para os cursos de pós-graduação, normalmente, os alunos eram enviados para Londres ou para outras universidades bem conhecidas no Reino Unido.

De acordo com a tradição colonial britânica, o Departamento de Estudos Clássicos, juntamente com Inglês, História e Estudos Religiosos era um dos departamentos fundamentais na Faculdade de Artes e Ciências Humanas. Nesse período em Londres (1950-1964), em sua maioria, os funcionários tinham diplomas de Oxford, Cambridge e Londres. Nomes importantes desse período que você talvez conheça são Professores J. Ferguson (1956-1966) e L. Thompson (1956-1995), que estabeleceram a base rigorosa para a primeira geração de classicistas nigerianos na universidade, começando pelo Professor Ilevbare, que, como Professor de Língua Grega, foi associado aos Estudos Clássicos em Ibadan de 1965 a 2004 e foi o primeiro funcionário a obter um doutorado de Ibadan (em "Aspectos da assimilação cultural no Norte da África nos períodos Cartaginês e Romano ${ }^{7 \prime \prime}$ ). Com Ibadan, os classicistas na UKZN compartilham o Professor K.D. White (outro formado em Cambridge) que, depois de sair de Pietermaritzburg em 1962, passou três anos em Ibadan.

O que foi importante durante o período de Ferguson e Thompson é que ambos entendiam que, para que o estudo dos Clássicos sobrevivesse na Nigéria pós-colonial, a África teria que ter um lugar importante no programa de pós-graduação. Já em 1962, o ano no qual a Universidade obteve sua autonomia, um curso obrigatório sobre a África na Antiguidade Clássica foi incluído no programa de pós-graduação. Além disso, nos anos 60, menos ênfase era dada ao estudo de latim e grego e mais no que chamamos de cursos de Civilização Clássica, especialmente aos cursos focados na interação entre as culturas da bacia Mediterrânea antiga e a África e o Oriente Próximo ${ }^{8}$. Um estímulo adicional à pesquisa nesse período foi a criação da revista científica "A Nigéria e

\footnotetext{
${ }^{6}$ Para a história da Universidade de Ibadan, veja Goff, 2013:187-88. Para um relato detalhado da história do Departamento de Estudos Clássicos da Universidade de Ibadan, veja o Manual do Estudante 2012:1-5, publicado pelo Departamento.

7 Manual do Estudante 2012:34. Veja também Ilevbare, 1970:80-85; 1973:24-44; 1980.

8 Manual do Estudante 2012:2-3.
} 
os Clássicos" (Nigeria and the Classics) já em 1958 (o mesmo ano de Acta Classica). A revista, que parou de ser publicada em 1971, foi ressuscitada pelo Departamento em Ibadan em 1994 e se tornou um fórum interessante e animado para estudos comparativos de mitologias e literaturas grega/romana e nigeriana antigas, assim como para estudos de questões sociais, políticas, econômicas, filosóficas e outras questões da antiguidade que de alguma maneira se assemelham às complexidades da sociedade nigeriana moderna'.

No final dos anos 60 e início dos anos 70, o Departamento de Estudos Clássicos se focou em desenvolver seu próprio programa de pós-graduação e em produzir um par de doutores "em casa", os quais moldaram a atual geração de classicistas em Ibadan. Até 1998, o complemento ao quadro de pessoal havia aumentado para oito, o mais alto desde 1963 - agora, esse número é onze. Desses, dez têm diplomas de Ibadan, principalmente doutorados e muitos foram testados externamente pelas duas universidades em Gana que oferecem os Clássicos (Legon e Cape Coast). Os temas da maioria desses (de Mestrado e de Doutorado) revelam a extensão da ênfase comparativa em Ibadan: "Retratos de mulheres na dramaturgia romana e nigeriana" (MPhil 1997); "Medo da beleza das mulheres na literatura clássica e africana/Yoruba" (PhD 2001); "Superstição nos pensamentos clássicos e Yoruba" (PhD 2007); "Questões sociopolíticas e morais nas sátiras romanas e nigerianas" (PhD 2007); "Motivos econômicos no Imperialismo Romano na África" (PhD 2010); "Mobilidade social na Tripolitânia romana" (MA 2003); e "A relação patrono-cliente no final da República Romana e o estilo "Poderoso Chefão" na política nigeriana contemporânea" (registro atual de doutorado ${ }^{10}$ ).

Embora muito dessas pesquisas tenha chegado aos cursos atualmente ofertados em Ibadan, cursos como "Civilização Grega na África e o Oriente Próximo"; "História Antiga e Arqueologia do Nordeste da África"; “História Antiga e Arqueologia do Magrebe" e "Direito Romano e Relações Internacionais", cursos tradicionais em língua e literatura grega e latina, bem como Epigrafia e Historiografia Grega e Latina são ofertados em vários níveis. Cursos básicos ainda duram quatro anos e, no ensino das línguas clássicas, tipicamente, dois anos são necessários para adquirir as habilidades básicas do idioma, antes de proceder para o estudo das literaturas contextualizadas nos últimos dois anos.

\footnotetext{
9 Como alguns dos títulos dos artigos em uma edição recente (2009) da revista científica ilustram: "O significado filosófico dos ritos matrimoniais romanos e Igbo", "Transculturalismo nos cantos corais de Mulheres Troianas de Eurípides e de Mulheres de Owu de Osofisan", "Recriação de Édipo Rei com humor Yoruba". Monografias de um membro do departamento também revelam a natureza comparativa da pesquisa clássica em Ibadan: veja Onayemi, 2004, 2010.

${ }_{10}$ Manual do Estudante 2012:34-38.
} 
O MA é ministrado com uma certa quantidade de cursos obrigatórios tendo como objetivo melhorar o conhecimento dos candidatos de grego e latim antes de procederem para o MPhil e o $\mathrm{PhD}$, que exigem teses. Candidatos a um MPhil tem que saber interpretar textos em francês ou em alemão e os candidatos ao doutorado tem que saber francês, alemão e/ou italiano.

Com onze funcionários e vários cursos sendo ofertados, o que causaria inveja a muitas universidades europeias ou americanas (e também a uma sul-africana), alguém poderia pensar que o número de matrículas é muito elevado ${ }^{11}$. Porém, esse não é o caso. Dos 20.000 alunos em Ibadan, aproximadamente 2.500 estão matriculados nos cursos oferecidos pela Faculdade de Artes e Ciências Humanas $(12.5 \%)^{12}$. Aproximadamente 100 alunos in toto estão matriculados nos cursos de Civilização Clássica e de Línguas Clássicas. Entretanto, esse número é mais do que triplicado por alunos de fora do Departamento de Estudos Clássicos e da Faculdade de Artes e Ciências Humanas (como, por exemplo, de Direito), que se matriculam nos cursos de Latim para Advogados, dois cursos de Direito Romano, um curso sobre o contexto histórico do Novo Testamento e cursos sobre a tradição Clássica na literatura inglesa e francesa ${ }^{13}$.

Quando eu comentei sobre o número relativamente pequeno de alunos em relação ao complemento do quadro de funcionários, alguns deles responderam que Ibadan não estava interessada em "massificação" e que eles realmente acreditavam que, quanto menores as turmas, melhor seria a qualidade da educação.

Então, como foi que Ibadan conseguiu fazer isso? Como aconteceu na África do Sul, o ensino de latim desapareceu das escolas nigerianas. A Universidade de Ibadan é a única universidade na Nigéria que manteve seu Departamento de Estudos Clássicos. Por quê?

Primeiramente, o Departamento se promove muito bem e tem um perfil público invejável, que se estende muito além dos portões da universidade. Nos panfletos publicitários que divulgam o trabalho do departamento, os classi-

11 O Manual do Estudante 2012:9-10 lista 60 cursos.

12 O número de matrículas em Educação, Ciências e Ciências Sociais está mais alto. Obtive essas estatísticas de um panfleto publicado pela Unidade de Planejamento da Universidade de Ibadan, dado a mim pelo Diretor e Vice-Reitor, durante uma entrevista entre mim, o diretor e um membro sênior do Departamento de Estudos Clássicos na Universidade de Ibadan (sexta-feira, dia 9 de novembro de 2012).

${ }^{13}$ Na Universidade de Ibadan, há um Departamento de Estudos Europeus, que ensina Francês, Alemão e Russo. 
cistas argumentam que o estudo de grego e latim, bem como o estudo das culturas grega e romana, em sua totalidade complexa, "são excelentes ferramentas para o trabalho, aprendizados futuros, insights sobre si mesmo e para o desenvolvimento de habilidades"; o estudo dos Clássicos, argumenta o autor do texto do folder do departamento, prepara "o aluno, por meio da educação Clássica comparativa com um maior apreço pelos valores de seu ambiente sociocultural, político e econômico"; o objetivo do departamento é "produzir graduados competentes e meticulosos, com a capacidade de fazer análises críticas em carreiras relevantes, que exigem discernimento sólido e balanceado, tais como: Administração, Jornalismo, Finanças e Setor Bancário, Educação, Direito e Diplomacia ${ }^{14}$."

Em segundo lugar, o Departamento acompanha seus ex-alunos e relaciona os formados em Estudos Clássicos que se destacaram em diversas áreas: administradores escolares, servidores públicos do alto-escalão, diplomatas e oficiais de chancelaria, líderes do comércio, finanças, setor bancário e indústria, advogados, escritores criativos, jornalistas, executivos do rádio e da TV. Na Palestra do Memorial Leventis, dada por mim, o presidente da sessão era o pró-Reitor e Presidente do Conselho da Universidade de Lagos, Dr. G. Onosode, ele próprio formado em Estudos Clássicos na década de 50, que também é um dos homens mais ricos da Nigéria. Para comemorar o jubileu de ouro de sua formatura em Ibadan, do seu primeiro curso, uma de suas empresas doou dez milhões de nairas para cada um dos cinquenta anos. Os bem cuidados jardins públicos da universidade receberam o nome em homenagem a ele. Membros do Departamento de Estudos Clássicos me disseram que ele é seu patrono e, frequentemente, doa dinheiro para a compra de livros para a biblioteca do departamento, bem como para pagar viagens a congressos e workshops no exterior.

Fica claro que o apoio do Dr. Onosode ao Departamento de Estudos Clássicos e seu prestígio na sociedade nigeriana como um todo refletem uma das caraterísticas da política nigeriana - a rede de relações patrono-cliente que parecem sustentar e lubrificar (creio que esta seja a palavra mais apropriada) o funcionamento (e em alguns casos o não funcionamento) da sociedade nigeriana. Certamente, em seu discurso apaixonado para a plateia, em grande parte composta por delegações de crianças em idade escolar, na palestra Leventis, sua defesa de sua educação clássica, algumas vezes, tocou no que os colonos britânicos alegavam sobre o valor de uma educação clássica na busca e gestão do seu império. Essa extraordinária aliança entre os Estudos Clássicos e a grande indústria embasa a própria Palestra Leventis. Constantine Le-

${ }_{14}$ Veja o Manual do Estudante 2012:5 - o programa para a 4a Bienal Palestra Memorial Constantine Leventis 2012:12. 
ventis (1938-2002), que lia os Clássicos na Universidade Clare, em Cambridge, ganhou seus milhões na Nigéria e em Gana estabelecendo indústrias que fabricam tampas de garrafa e fazem cerveja ("Cervejarias Continental”). A palestra Memorial Leventis é feita em sua homenagem. Representantes da Fundação Leventis estavam presentes durante a palestra. Esta fundação tem apoiado o desenvolvimento dos funcionários do Departamento de Estudos Clássicos na universidade e disponibilizou dinheiro para livros e prêmios para o(a) melhor aluno(a) de Estudos Clássicos em cada ano da graduação, assim como um prêmio para o(a) melhor aluno(a) de pós-graduação. Em terceiro lugar, além desse casamento produtivo com os capitães da indústria (falecidos e vivos), o Departamento mantém uma conexão saudável com escolas locais que poderiam fornecer os alunos para a universidade. As crianças chegaram ao local da palestra de ônibus e chegaram em massa. Elas foram encorajadas a fazer perguntas (pelo Dr. Onosode) depois da palestra (e algumas assim o fizeram); e eu tive que tirar fotos com cada escola depois da palestra. Panfletos sobre os Clássicos e sobre o trabalho do departamento foram distribuídos depois da palestra e havia mesas cheias de publicações dos membros do departamento, inclusive com volumes de versos em inglês, o que atraiu atenção para a conexão feita entre os Estudos Clássicos e a vida literária nigeriana. Constantemente, o periódico Nigéria e os Clássicos também publica artigos de natureza interdisciplinar de colegas dos departamentos de Inglês, Línguas Europeias e Estudos Religiosos. Na verdade, membros do departamento de Estudos Clássicos garantem ter um perfil elevado na vida social e cultural nigeriana, de modo geral. O ex-Diretor do Departamento havia participado de uma conferência sobre Estudos de Gênero na Etiópia e tinha retornado para escrever dois poemas sobre mutilação genital feminina, que se tornaram famosos nos círculos ativistas de direitos humanos ${ }^{15}$.

Em quarto lugar, o Departamento não apenas mantém conexões com escolas, mas também fomenta uma animada Associação Clássica chamada "Hoi Phrontistai", que é gerenciada pelos alunos, que elegem seu próprio executivo. Esta associação preside o Clube de Imprensa dos Clássicos, seus membros escrevem artigos, poemas, músicas e piadas, normalmente, sobre a vida no campus, que são publicados toda semana no quadro de avisos do departamento. Além disso, os alunos gerenciam um programa de orientação para calouros, um concurso de oratória e um concurso interdepartamental de debates. Adicionalmente, os alunos de Estudos Clássicos têm seu próprio time de futebol que, aparentemente, é poderoso e difícil de vencer. A sessão da qual participei com os alunos foi muito bem presidida pelo diretor da "Hoi Phrontistai".

15 Veja Onayemi, 2006:73, 76-78. 
Até o momento, eu respondi à pergunta "Como?", mas não a pergunta "Por quê?". Qualquer classicista que se preze está tão enraizado na "hermenêutica da suspeita" que nunca acreditamos em algo logo de cara. Consequentemente, eu tentei descobrir se houve alguma falha perceptível no discurso bastante público sobre o sucesso dos Clássicos em Ibadan. Havia alguma dissonância entre a retórica pública nos panfletos, folhetos, periódicos (e no que os membros do departamento me contaram) e o que estava realmente acontecendo nas salas de aula e nos exames? Eu aguardei com ansiedade por minha conversa com os alunos.

Esta conversa aconteceu na biblioteca do departamento cheia de livros e periódicos, alguns recentemente doados pela Fundação Leventis e pelo Dr. Onosode. Não havia funcionários presentes. Eu imaginei que iria dar uma palestra sobre como ler versos gregos e latinos e tornar tudo mais divertido.

Meu propósito era realmente avaliar o quanto de grego ou latim os alunos sérios e dedicados de Estudos Clássicos sabiam. Rapidamente descobri que isso não estava funcionando, portanto, mudei os planos e comecei a discutir os textos de Safo e Cátulo, que havia escolhido, no contexto mais animado e vulgar possível. Dentro de minutos, percebi que telefones celulares começaram a aparecer discretamente e que a plateia, que inicialmente tinha sido pequena, quase dobrou. Sexo vende bem. Depois, parei a palestra e fiz várias perguntas sobre os seus cursos. Em primeiro lugar em suas mentes, estava a seguinte pergunta: a propaganda departamental, que alegava que o estudo dos Clássicos poderia resultar em empregos em todos os tipos de profissão, do setor de finanças/bancário até o direito, era verdadeira? O que faziam os nossos alunos de pós-graduação (em Estudos Clássicos)? Então, fiquei em uma situação difícil - como convidado do departamento, eu não queria subverter a propaganda departamental. No entanto, eu também não queria dar a impressão de que o estudo dos Clássicos, em essência, oferecia algum tipo de entrada universal a uma infinidade de profissões. Portanto, tentei ser o mais diplomático possível e disse claramente que tudo dependeria dos tipos de Clássicos estudados e de quais habilidades seriam adquiridas durante o curso.

Deixe-me dar um exemplo. Tentei achar algumas provas (porque estava na época de exames) e selecionei dois cursos Clássicos - um curso de máximas jurídicas em latim e o outro sobre história política republicana romana. O curso de máximas jurídicas consistia de listas de máximas (tais como: acerrima proximorum odia - o ódio dos parentes mais próximos é o mais amargo - ou caveat emptor e lis pendens), que tinham que ser traduzidas e colocadas em um contexto jurídico, seguidas de gramática bem básica de latim. A memorização de longas listas de frases em latim jurídico, com as quais alguém poderia apimentar uma conversa, para mim, parecia ser particularmente sem sentido e de pou- 
co real valor educacional, mas isso era claramente considerado treinamento valioso se alguém quisesse fazer parte da elite intelectual nigeriana. $\mathrm{O}$ curso de história republicana, por sua vez, forçava os alunos a compararem aspectos da história colonial da Nigéria à luta das ordens na República Romana e à ascensão do imperialismo romano na Itália. Baseado no exame, parecia que esse curso exigia muito mais do que memorização e de fato equipava os alunos com as habilidades analíticas que o departamento alegava transmitir.

Depois, eu conversei com alguns alunos de pós-graduação e houve reclamações sérias sobre as inadequações da biblioteca, apesar das doações da Leventis e do apoio do Dr. Onosode. Além disso, uma aluna de doutorado, que leciona no departamento, mencionou que estava tendo problemas com as metodologias de pesquisa porque ninguém nos Estudos Clássicos sabia coisa alguma sobre elas e havia pressão do departamento de Ciências Sociais, em especial, para que os alunos dos Clássicos moldassem suas propostas de pesquisa dentro de epistemologias mais amplas. Também fui informado de que ela havia discordado do seu orientador sobre questões de metodologia e que ele havia chamado a ela e a seu marido ao seu escritório, depois do expediente, para que eles se prostrassem diante dele e pedissem desculpas. Conforme ela comentou: "Como podemos ser pensadores independentes e críticos em um ambiente assim?"

Havia um membro do departamento que eu só conheci no meu último dia lá. Ele fazia parte do quadro desde 1975 e tinha dado aulas para todos os membros do departamento atual. Inicialmente, ele pareceu muito desconfiado de mim, mas respondeu todas as minhas perguntas honestamente. Não havia nenhuma propaganda departamental dele, mas um fluxo bem cínico de afro-pessimismo, que era bastante deprimente, porém, (eu suspeito) um corretivo necessário para a propaganda utópica que eu tinha recebido. Afora suas críticas à universidade como tal ${ }^{16}$, ele não achava que os padrões em Ibadan estavam tão elevados como costumavam ser, embora ele claramente sentisse muito orgulho do que o departamento havia alcançado. Ele havia ministrado a aula principal de Grego naquele ano e os alunos haviam lido 200 linhas de Hesíodo e alguns poemas de Safo naquele semestre. Expliquei o que nós normalmente faríamos com nossos alunos em um semestre e ele comentou que não achava que os alunos de pós-graduação de Grego de Ibadan conseguiriam ler um livro de Homero no original. Na pergunta mais abrangente: por que estudar os Clássicos? Ele sugeriu que suspeitava que o estudo dos Clássicos simplesmente ajudaria a perpetuar a elite intelectual e política que dominava todos os aspectos da sociedade nigeriana.

\footnotetext{
16 A entrega ao gerencialismo, o cínico "jogo dos números" - muitas das suas críticas podem ser aplicadas a universidades na África do Sul contemporânea.
} 
Eu ainda não estava totalmente convencido de que havia recebido respostas convincentes para a pergunta: "Por que estudar os Clássicos na Nigéria dos dias atuais?". Em resposta a esta pergunta, um outro aluno de doutorado, que está trabalhando com o tema relações patrono-cliente romanas e o estilo "Poderoso Chefão" na Nigéria contemporânea (isso é muito comum nas teses nigerianas sobre os Clássicos), argumentou o seguinte: as culturas antigas da Grécia e de Roma são universalmente admiradas - e é por isso que as chamamos de "Clássicos"; ao comparar problemas africanos àqueles enfrentados pelos gregos e romanos e as soluções que eles ofereciam, ele estava sugerindo que os problemas africanos também são dignos de respeito e análise. Talvez os gregos e romanos possam nos ajudar ao olharmos para o passado e observarmos que experimentos eles fizeram e como falharam ou obtiveram sucesso. Como um corolário disso, ele comentou sobre o fato de que todas as melhores universidades na África e no mundo têm departamentos de Estudos Clássicos. Ibadan é a melhor universidade na Nigéria. Ibadan deve manter os Clássicos. De várias formas, seu discurso se mesclou com o de alguns membros do departamento que haviam ido a congressos no exterior ou haviam aceitado bolsas de pós-doutorado de excelentes universidades, tais como Brown, Austin (Texas) e Oxford e haviam trabalhado na Escola Britânica de Atenas. Discursos sobre o estudo dos Clássicos na Nigéria claramente ligados a discursos exclusivistas similares sobre o valor de uma educação clássica em instituições para a elite como Brown e Oxford.

Há muito aqui que podemos aprender com o Departamento de Estudos Clássicos em Ibadan, especialmente sobre como fazer a divulgação da disciplina dentro de uma teia complexa de relações entre os funcionários acadêmicos e a administração da universidade, entre os funcionários e ex-alunos, entre os funcionários e alunos de Estudos Clássicos, entre alunos de Estudos Clássicos e "outros", entre o departamento e as escolas locais. O que me impressionou foi que eu não ouvi o debate Eurocêntrico/Afrocêntrico ou os "sistemas de conhecimento indígena" serem mencionados nenhuma vez. Nenhum aluno, por exemplo, havia ouvido falar da hipótese de Bernal "Atenas Negra”. Quando desenhei os contornos do debate Eurocêntrico/Afrocêntrico aqui, o ex-diretor do departamento murmurou: "Oh, por favor, nós passamos por isso nos anos 60." Os classicistas nigerianos em Ibadan realmente se apropriaram dos Clássicos; quando mencionam grandes industriais ou renomados administradores que tiveram treinamento clássico, eles estão falando de seus companheiros nigerianos que merecem ser imitados, não colonos britânicos ou seus clones. Não estou dizendo que os nigerianos despolitizaram os Clássicos - o ensino dos Clássicos está obviamente embutido nas relações de poder entre as hierarquias que controlam a sociedade nigeriana - mas eles descolonizaram os Clássicos e se apropriaram do que acham ser significativo. 
Agora, de que maneira a crítica de Mamdani da "cultura da consultoria" nas universidades africanas resiste sob a luz das minhas experiências em Ibadan? Vamos começar com algumas das questões mais simples. Claramente, Ibadan avançou além de Makerere em Uganda; conforme eu já mencionei, a maioria dos doutorados em Estudos Clássicos em Ibadan são "caseiros". Sobre a "massificação" da educação na Nigéria, eu acho que ele está correto e os funcionários estão errados. Minha breve entrevista com o Diretor e Vice-Reitor indicou que o "jogo dos números" era muito importante para ele. O simples fato de que o Departamento de Estudos Clássicos tenha criado um curso de frases em latim no Direito romano é realmente sobre aumentar o número de alunos de Clássicos e estender o alcance dos Clássicos até outras Faculdades. Eu acho que muitos de nós já tenhamos usado este estratagema: entrelaçar os Clássicos com outras disciplinas o máximo possível, para que se torne quase impossível separá-las. A excelente proporção aluno-funcionário em Ibadan está ligada à política local da universidade e também ao relacionamento com o Dr. Onosode e a Fundação Leventis. Os departamentos de Estudos Clássicos em Gana, por exemplo, não têm tantos funcionários e Legon e Cape Coast têm que compartilhar professores.

Em relação à "cultura de consultoria", Mamdani, como diretor de um Instituto de Pesquisas Sociais, obviamente, enfatizou sua experiência em agências internacionais, think-tanks e fundações, que usam a África como um reservatório de "dados" valiosos. Como ele mesmo diz: "o mercado global tende a relegar a África ao fornecimento de insumos ("dados") para acadêmicos de outros países, que os processam e, depois, reexportam suas teorias de volta para a África." Você pode acreditar que este é claramente o domínio das Ciências Sociais, que tem pouco a ver com o estudo dos Clássicos, enraizado como é nas pesquisas baseadas em textos, o que não envolve o tipo de coleta empírica de informações que Mamdani tem em mente. Entretanto, foi exatamente por causa das metodologias, muitas delas importadas das Ciências Sociais, que a aluna de doutorado em Estudos Clássicos em Ibadan teve conflitos com o seu orientador. Como muitos de vocês devem saber, a maioria das propostas de pesquisa de pós-graduação na área de Humanidades nas universidades sul-africanas, agora, exige certo conhecimento de metodologias de pesquisa e a tão temida análise da literatura ${ }^{17}$. Nossos alunos, caso estejam trabalhando nos épicos de Homero ou nos discursos de Cícero, têm que saber o que são as metodologias de pesquisa qualitativas e quantitativas, quais epistemologias as sustentam e como a metodologia escolhida os coloca em uma tradição intelectual específica, que, de forma alguma, é a única. Um dos meus alunos de

\footnotetext{
${ }_{17}$ Na verdade, na Universidade de KwaZulu-Natal, um trabalho sobre metodologias de pesquisa, agora, é obrigatório para todos os alunos honorários de Estudos Clássicos (e outros).
} 
Mestrado trabalhando em mágica antiga comparativa greco-romana e Zulu teve que aprender técnicas de entrevistas, elaborar questionários e processar dados da mesma forma que um aluno de Antropologia, Sociologia ou Psicologia. Na verdade, se os nossos alunos embarcarem nos tipos de projetos comparativos que os alunos nigerianos realizam, então, os tipos de técnicas de pesquisa que os cientistas sociais ou políticos utilizam também têm que ser aprendidos. Caso gostemos ou não, os limites entre as Ciências Humanas e as Ciências Sociais se tornaram tão porosos que fica difícil definir o nosso território disciplinar. Além disso, alguns Departamentos de Estudos Clássicos aqui na África do Sul se tornarem parte de grupos interdisciplinares mais amplos, tais como Escolas de Religião, Filosofia e Estudos Clássicos, ou Escolas de Idiomas e Literaturas, o que já resultou no tipo de pensamento interdisciplinar exaltado por Mamdani. Ademais, nós, como classicistas, estamos no lugar certo para esse tipo de pesquisa porque temos feito isso há muito tempo. Quantos de nós percebemos que damos aulas de literatura clássica, mitologia, filosofia, religião, história, política, artes, arquitetura, sem mencionar gênero, sexualidade, medicina, cinema, grego e latim e, por vezes, tudo em uma semana? Estamos acostumados a trabalhar em um paradigma interdisciplinar, mas o desafio de Mamdani, que deveríamos nos perguntar constantemente, que paradigma intelectual molda as nossas perguntas de pesquisa e se elas são apropriadas para a África, é uma que deveríamos responder.

O que também precisamos responder é o tipo de asserção de autoridade patriarcal e as hierarquias sociais presentes na relação orientador-aluno em um contexto africano. Como mencionei anteriormente, a aluna de doutorado, juntamente com seu marido, teve que se prostrar perante seu orientador como um pedido de desculpas. Atualmente, esse tipo de cortesia Yoruba tradicional é comumente praticada por alunos na Universidade de Ibadan, quando eles cumprimentam os funcionários em seus escritórios e até mesmo para algo tão simples quanto solicitar uma carta de referência. Os mais jovens se prostrando perante os mais velhos (independentemente do sexo) não tem nada a ver com os paradigmas intelectuais Ocidentais pós-Iluminismo, mas trata-se de uma prática cultural africana que, como a aluna mesma disse, é inimiga do tipo de pensamento crítico e independente que uma educação universitária deveria estar estimulando. Mesmo se essa reverência persistir devido a uma espécie de nacionalismo cultural pós-independência, evitando que os aspectos da cultura Yoruba se percam em uma Nigéria multiétnica, sua prática em um ambiente universitário precisa ser questionada. Não apenas paradigmas intelectuais Ocidentais, mas práticas culturais, atitudes e tradições africanas precisam ser submetidas ao mesmo escrutínio se uma universidade verdadeiramente africana, com um etos de pesquisa independente, é para ser fomentada. 
Tudo bem questionar os paradigmas pós-Iluminismo que sustentam os nossos projetos de pesquisa, mas de que maneira podemos, como uma associação de classicistas, fomentar o tipo de interesse e comprometimento que garanta que tenhamos um fluxo constante de alunos equipados para fazerem essas perguntas? O que podemos fazer para criar interesse nos Estudos Clássicos fora da academia para garantir que a nossa sobrevivência não fique confinada ao gueto universitário onde, em alguns casos, a espada de Dâmocles, que pode ter enferrujado nos últimos anos, parece ter adquirido um brilho novo?

Para que possamos tentar responder a isso, eu gostaria de discordar de Mamdani e usar o trabalho do filósofo contemporâneo alemão Jurgen Habermas, especialmente, seu bem conhecido: A Transformação Estrutural da Esfera Pública. Ao questionar os paradigmas intelectuais dominantes que estão influenciando a pesquisa na África, Mamdani se refere especificamente ao Iluminismo com esta pergunta: "se o Iluminismo é considerado um fenômeno exclusivamente europeu, então, a história do Iluminismo exclui a África e também a maior parte do mundo. Será então que essa é a base sobre a qual podemos construir a educação universitária na África?" A oração condicional de Mamdani é especialmente importante.

No trabalho de Habermas, ele analisa os processos que resultaram em mudanças intelectuais, políticas e sociais na Europa, marcadas pela Revolução Francesa e a mudança para o republicanismo e a democracia e foca no que, para nós, pode parecer trivial - cafeterias do século XVIII em Londres, nas quais a abertura a ideias e o engajamento crítico, característicos do Iluminismo, se enraizaram dentre as pessoas, particularmente os burgueses, onde a "esfera pública", como sabemos agora, foi forjada. Entretanto, em nenhum momento, Habermas afirma que o Iluminismo foi um evento fixo, como Mamdani parece fazer, mas como um "projeto" que ainda está em andamento e não necessariamente confinado às regiões costeiras da Europa. Eu já mencionei como os classicistas da Nigéria distribuem suas publicações para crianças em idade escolar, assim contribuindo para moldar uma consciência sobre os Clássicos na classe média nigeriana educada, mas não apenas sobre os Clássicos. Alguns dos poemas de um classicista em Ibadan lidam com a política nigeriana contemporânea com uma raiva selvagem e, portanto, fazem alguma contribuição, mesmo que seja apenas ínfima, à possível transformação da esfera pública e ao avanço do "projeto" do Iluminismo. O que o exemplo da cafeteria de Habermas ilustra é como a transformação de paradigmas intelectuais não começa no topo, mas embaixo, ou melhor, em algum lugar no meio. $\mathrm{Na}$ Associação Clássica da África do Sul, precisamos ressuscitar nossas filiais locais, se elas estiverem inativas, nossas palestras em museus e associações, tais como a Universidade da Terceira Idade, e novamente focar nas escolas, as quais, desde o fim das aulas de latim, nós mais ou menos abandonamos. A 
sugestão de que deveríamos investigar a introdução do estudo da Civilização Clássica (no modelo Antipodal) em nossas escolas é muito boa - você deve se lembrar dos nossos esforços para fazer isso no início da década de 90, o que resultou na publicação de duas cartilhas que eu editei. Latim ainda estava sendo ministrado naquela época e esse curso foi usado para ampliar o programa de estudos de latim. Era difícil conceber que, naquela época, a Civilização Clássica era alguma coisa além de uma humilde ancilla do ensino dos idiomas, mas, nesta era pós-idiomas, acho que chegou a hora de criar uma proposta, um programa de estudos e consultar as autoridades necessárias no Departamento de Educação. Desta forma, podemos contribuir para a formação de uma nova geração de alunos que poderão chegar às nossas universidades com algum conhecimento do que fazemos e quão transformativo isso pode ser.

Uma estrutura em forma de anel, como constantemente ensinamos nossos alunos, é importante em qualquer composição clássica, então, agora, volto às perguntas sobre arcos-íris e borboletas. O discurso "nação arco-íris" se tornou um tanto quanto desgastado e passé na África do Sul, principalmente por causa da óbvia dissonância entre a retórica política e a experiência vivida que se tornou difícil demais para suportar. Entretanto, imagine como seria se, daqui a vinte anos, um classicista não sentisse a necessidade de "problematizar" uma questão aparentemente inocente em uma aula de Língua Grega I em uma universidade sul-africana e borboletas, que são agora muito raras, não tivessem que servir como uma metáfora para os classicistas, espetadas em quadros em museus empoeirados.

\section{Bibliografia}

Goff, B. 'Your Secret Language' Classics in the British Colonies of West Africa. London: Bloomsbury, 2013.

Habermas, J. The Structural Transformation of the Public Sphere. Transl. T. Burger. Cambridge, Mass.: MIT Press, 1989.

Ilevbare, J.A. 'The language and process of cultural assimilation in ancient North Africa.' Nigeria and the Classics 12, 1970, 80-85.

Ilevbare, J.A. 'Some aspects of social change in North Africa in Punic and Roman times.' Museum Africum 2, 1973,24-44.

Ilevbare, J.A. Carthage, Rome, and the Berbers. Ibadan, 1980.

Lambert, M. The Classics and South African Identities. London: Bloomsbury \& Bristol Classical Press, 2011. 
Mamdani, M. 'The importance of research in a University.' Keynote address, Makerere University Research and Innovations Dissemination onference, Uganda, 27 April 2011.

Nigeria and the Classics 25 (2009) 1-82. Journal of the Department of Classics, University of Ibadan. Ibadan, Nigeria.

Onayemi, F. (Yoruba) Literature. Ibadan: Hope Publications, 2004.

Onayemi, F. Each Shaft of the Sun. Ibadan: The Postgraduate School, University of Ibadan, Nigeria, 2006. The Nature and Language of Love in Ancient Roman and African

Onayemi, F. Parallels of Ancient Greek and African/Yoruba Gods. Akropong-Akuapem, Ghana: NeatPRINT Publications, 2010.

Pocket Statistics Planning Unit, Office of the Vice Chancellor, University of Ibadan, Ibadan, Nigeria, 2010.

Lecture Programme 2012. 4th Biennial Constantine Leventis Memorial Lecture. Ibadan: SapphirePrints.

Students Handbook 2012. Department of Classics. University of Ibadan, Ibadan, Nigeria. 